DOI 10.20396/temáticas.v11i21/22.13525

\title{
OS MECANISMOS DE EXCLUSÃO DO TRABALHO FEMININO EM UMA EMPRESA ${ }^{1}$ EM PROCESSO DE REESTRUTURAÇÃO
}

\section{Cátia Regina Muniž²}

RESUmo: O presente trabalho aborda os mecanismos de exclusão constatados no estudo dos processos de mudança ocorridos em uma fábrica localizada no interior do estado de São Paulo, com filial em Recife, ligada a um grupo anglo-holandês. Neste artigo, a ênfase recai sobre as formas de exclusão do trabalho feminino praticadas na área produtiva da referida fábrica: no processo seletivo, nas ocasiões de afastamento e retorno ao trabalho, por motivos de gravidez ou doença, quando as operárias são postas na categoria de alocadas.

UNITERMOS: Reestruturação produtiva; mecanismos de exclusão; dimensão simbólica; processos de mudança.

O objetivo deste artigo é destacar como ocorre, na empresa estudada em minha dissertação de mestrado- em específico a fábrica localizada na cidade de Vinhedo, interior do Estado de São Paulo, tendo ainda, como exemplo comparativo, sua filial localizada na cidade de Recife, no Estado de Pernambuco- o processo de seleção interna praticado pela empresa, na qual será dada maior ênfase à área produtiva. Como poderemos verificar, apesar de

\footnotetext{
${ }^{1}$ A fábrica mencionada foi pesquisada em minha dissertação de mestrado, pertencendo a uma empresa no Brasil, que, por sua vez, é ligada a um grupo anglo-holandês. Esta fábrica produz linhas de produtos pessoais tais como: desodorantes, shampoos, sabonetes líquidos, cremes hidratantes, cremes dentais.

${ }^{2}$ Este artigo faz parte da minha dissertação de mestrado, defendida em agosto de 2001 no Instituto de Filosofia e Ciências Humanas da Universidade Estadual de Campinas (UNICAMP).
}

Temáticas, Campinas, 11(21/22):49-74, jan./dez. 2003 
um discurso da empresa em oferecer "iguais" oportunidades tanto aos trabalhadores quanto às trabalhadoras, ocorrem exclusões em determinados cargos, baseadas no sexo do (a) trabalhador (a). A pesquisa de campo mostrou estas diferenciações na ocupação dos cargos oferecidos pela empresa, fazendo com que acabasse por dar uma maior ênfase nos conflitos de gênero observados na fábrica estudada, privilegiando, de certa forma, a discussão da situação vivenciada pelas trabalhadoras, que se mostrou extremamente relevante.

Além disto vários trabalhos (Abreu, 1993; Hirata e Kergoat, 1994; Segnini, 1998, entre outros) já demonstraram que a classe operária não é unívoca e não pode ser pensada como homogênea. Segundo Hirata e Kergoat (1994) a partir da construção do conceito de gênero por antropólogos e sociólogos nos anos 70, torna-se evidente que os conceitos chave do marxismo para lutar contra a exploração eram insuficientes para mostrar a opressão sofrida pelas mulheres "quanto às relações homem/mulher no seio da sociedade” (Hirata e Kergoat, 1994: 94). Estas autoras afirmam que,

foi preciso primeiro tornar visível a construção histórica, cultural, do sexo social (ou gênero) contra o naturalismo e o fatalismo que impregnam a representação da mulher como inferior, subordinada por razões de ordem biológica; é clara a analogia com a naturalização das raças dominadas a partir de diferenças biológicas (Hirata e Kergoat, 1994: 94-95).

Estas autoras consideram os atores individuais e coletivos como não só produto das relações sociais, mas também, produtores destas relações e é sob esta perspectiva que os (as) operários (as) serão tratados neste artigo.

Alice Rangel de Paiva Abreu (1993) acrescenta que se como algumas autoras afirmam, "a classe operária ter dois sexos", então as mudanças implementadas pelas empresas devem ser entendidas a partir de uma perspectiva de gênero. Toda esta discussão corresponde ao propósito deste trabalho que é considerar as diferenças na construção das representações dos operários e operárias sobre seu cotidiano de trabalho tendo como foco principal as relações de poder estabelecidas na área produtiva, que têm pro- 
vocado exclusões de trabalhadores e, principalmente, de trabalhadoras dos grupos de trabalho tornando-se o que denominam de "alocados".

\section{O PROCESSO DE SELEÇÃO INTERNO E A SITUAÇÃO DE "ALOCADOS"}

Danièle Combes e Monique Haicault (1986) colocam uma questão muito interessante que demonstra bem o que vem ocorrendo na área produtiva da fábrica estudada. Para estas autoras não se pode mais pensar que há uma aliança entre trabalhadores e trabalhadoras para lutarem contra o capital,

esquecendo suas divergências como se fossem brigas de casal para serem resolvidas em outra instância, nos lares ou, como se costuma dizer, na esfera privada, até mesmo nas alcovas (...) (grifo das autoras) (Combes e Haicault, 1986: 29).

$\mathrm{Na}$ área produtiva da fábrica estudada não há união entre trabalhadores e trabalhadoras, ao contrário, vem ocorrendo muitos conflitos entre eles. Desde 1990, a empresa em questão implementou, na área produtiva, o trabalho semi-autônomo, semelhante ao da fábrica da Volvo na Suécia, ou seja, os trabalhadores atuam em grupos e possuem uma certa "autonomia" para decidirem como irão trabalhar e também escolherem os seus companheiros de produção.

Segundo vários relatos, o que tem sido privilegiado nesta escolha, é a relação de amizade com os candidatos e não a "competência" dos mesmos, o que tem provocado exclusões daqueles que não fazem parte do círculo de amizade do grupo. A exclusão das operárias nesta área é maior, pois se inicia, de acordo com diversos relatos, com o afastamento de trabalhadoras da rotina de seu trabalho por doenças geralmente a LER (Lesões por Esforço Repetitivo ${ }^{3}$ ), causadas principalmente pelo trabalho intensivo e repetitivo nos finais das

\footnotetext{
${ }^{3} \mathrm{Na}$ indústria estudada pela autora Anna Pollert (1996) também é observado por esta a LER que, como na fábrica estudada, é produto do aumento da velocidade e a intensidade do trabalho nas áreas de embalagens das linhas.
}

Temáticas, Campinas, 11(21/22):49-74, jan./dez. 2003 
linhas (embalagens), por algum acidente ou gravidez. As trabalhadoras nestas condições são afastadas de suas funções. São, deste modo, "alocadas" no setor produtivo ou administrativo, cujas funções são realizar tarefas em outros grupos que estejam sem um dos componentes ou auxiliar os coordenadores no trabalho de escritório, tais como xerox, preenchimento de formulários, entre outros. Numa das fábricas estudadas por Cibele Risek e Márcia Paula Leite (1998), haviam trabalhadoras denominadas de "reserva", que se encontravam numa situação semelhante a das "alocadas" na fábrica estudada, ou seja, trabalhadoras que, a cada dia, são escolhidas para abastecer as máquinas e para substituir outras operárias nas eventuais faltas e paradas.

A situação das "alocadas", como são chamadas as pessoas nestas condições, classificação esta elaborada na fábrica em Vinhedo, pois na sua filial localizada em Recife não há esta denominação, nesta última os trabalhadores e trabalhadoras em situação semelhante são chamados de "ajudantes de produção" pode ser considerada muito semelhante aos atributos de liminaridade na sociedade ndembo, do noroeste da Zâmbia, descrito por Victor Turner (1974):

As entidades liminares não se situam aqui nem lá; estão no meio e entre as posições atribuídas e ordenadas pela lei, pelos costumes, convenções e cerimonial. Seus atributos ambíguos e indeterminados exprimem-se por uma rica variedade de símbolos, naquelas sociedades que ritualizam as transições sociais e culturais. Assim a liminaridade freqüentemente é comparada à morte, ao estar no útero, à invisibilidade, à escuridão, à bissexualidade, às regiões selvagens e a um eclipse do sol ou da lua (Turner, 1974: 117).

E também nas crenças de pessoas em situação marginal estudada por Mary Douglas (1976):

Estas são pessoas que estão de algum modo excluídas do padrão social, que estão deslocadas. Podem não estar fazendo nada de moralmente errado, mas seu status é indefinível (Douglas, 1976: 118). 
Douglas cita, como exemplo, o feto na sociedade Lele, que tem uma posição ambígua, porque não se sabe qual será o seu sexo ou se sobreviverá aos riscos da infância, por isso é tratado como vulnerável ou perigoso e emana esse perigo aos outros. O perigo encontra-se também nos estados de transição, porque este é indefinível, afirma Douglas. Para que o perigo seja controlado, há um ritual que separa a pessoa "do seu velho status, a segrega por um tempo e, então publicamente declara seu ingresso no novo status" (Douglas, 1976: 199-120).

Tanto no caso citado por Turner como em Douglas, estão rituais de transição social e cultural. Na fábrica pesquisada, entretanto, as trabalhadoras "alocadas" assemelham-se mais, pelo próprio contexto social em que vivemos, à situação de ex-prisioneiros, também citado por Douglas, no que diz respeito à dificuldade em encontrar recolocação. No caso da fábrica pesquisada, seria a recolocação nos grupos. Segundo alguns relatos, dificilmente uma trabalhadora na situação de "alocada" consegue se reintegrar novamente em um grupo, por causa da maneira que estão sendo realizadas as escolhas dos integrantes desses grupos de trabalho. Contudo, no caso estudado, não deixa de haver um forte sentimento de ambigüidade e invisibilidade nesta situação, segundo relatos. Por exemplo, uma das operárias comentou que trabalhava em um grupo há seis anos, necessitou de afastamento por um mês, devido a problema causado pela LER (lesão por esforço repetitivo). Todavia esta ia todos os dias à linha ajudá-los com a parte teórica de um programa que estava sendo implementado na área, mas, mesmo agindo desta maneira, os integrantes do seu grupo alegaram que ela estava atrapalhando o andamento do mesmo, por isto não a aceitaram de volta. A atitude tomada pelo grupo foi a substituição desta operária por um outro trabalhador, que, segundo seus comentários, não havia tido ainda nenhum treinamento deste programa, e ela já havia passado por seis etapas do programa. $\mathrm{Na}$ interpretação desta operária, ela foi excluída do grupo por ser mulher: a mulher, eles fazem de tudo pra cbutar, afirma. Apesar dos trabalhadores da área comentarem que fazem o mesmo com os homens quando estes fi- 
cam doentes, um dos coordenadores relatou que é uma tendência na fábrica terem mais mulheres na condição de "alocada", por causa do próprio processo de escolha dos integrantes dos grupos. Diferente de outras empresas, na fábrica pesquisada, trabalhadores e trabalhadoras recebem a mesma qualificação, já que executam as mesmas tarefas, mas, como podemos ver no caso citado, muitas vezes, as trabalhadoras são impedidas de praticar seu treinamento porque estão fora dos grupos de trabalho.

A justificativa dos operários sobre as "alocadas" não voltarem mais para seus respectivos grupos, é a seguinte:

Aí o que acontece, se vai cada dia uma pessoa na linha você precisa ensinar e se for uma linha rápida, não dá tempo, e aí, no outro dia, vai uma outra pessoa diferente, então isso aí atrapalha. Tem grupo que opta por tirar a mulher neste caso, e aí ela vai fazendo um serviço paralelo, faz serviço de coordenador. Geralmente, escolhem homens para ficar no lugar (operário da linha de shampoo).

Um outro trabalhador relatou que sofrem uma certa pressão da empresa, confirmada por um dos coordenadores da área, para obterem maior produtividade, sendo este um dos motivos de substituição permanente no grupo de um colega afastado. Os trabalhadores são cobrados para que atinjam as metas estabelecidas de produtividade e de qualidade dos produtos, por isso quando o substituto é uma pessoa que tem um bom desempenho, optam por contituar com ela permanentemente. Esta justificativa, porém, não responde a questão da preferência por substitutos homens.

As trabalhadoras da manufatura comentaram sobre a condição de "alocada" quando estão em RAP (Recuperação da Atividade Produtiva), ou seja, quando saem de licença por motivo de doença, voltam a trabalhar, mas não a exercer suas antigas funções até se recuperarem totalmente. Por este motivo, realizam outras atividades que não prejudiquem sua recuperação. No entanto, segundo dizem, seus colegas homens acabam interpretando este estado como se elas não quisessem e não como se elas não pudessem trabalhar. Uma das operárias comentou que não volta a esta situação, pois não 
agüentará novamente passar por todas as humilhações que os trabalhadores da área a fizeram sofrer. Estes acham que, porque as “alocadas" em RAP estão na fábrica, já estão recuperadas para voltarem ao trabalho, afirma uma das entrevistadas. $\mathrm{Na}$ interpretação desta operária, seus colegas só acreditariam que ainda estão em recuperação se aparecessem na fábrica sentadas em cadeiras de rodas ou coisa parecida. Uma outra relatou que, se por acaso vão atender o telefone, tecem o seguinte comentário: Ô telefonista!!! Só atende telefone... Desabafa: Eu não agüiento isto. Eles acham que é frescura sua, afirma uma delas.

Um dos coordenadores da área produtiva confirma esta situação vivida pelas mulheres em RAP, na qual se sentem deslocadas e começam a ouvir boatos de que o grupo não as quer de volta, deixando as operárias muito deprimidas. Para este entrevistado, os grupos deveriam valorizar os trabalhadores e trabalhadoras que estão em situação de RAP, mas o que acontece é o esquecimento, por parte do grupo, de todo o trabalho desenvolvido por aquela pessoa durante o tempo em que fez parte do grupo. Novamente aparece, no relato, a questão da invisibilidade, para os demais grupos, destas pessoas, estas passam a não existir para o restante dos trabalhadores.

Norbert Elias (2000) comenta que no caso de um grupo estabelecido, em que os membros

são mais inseguros, mais incertos acerca de seu valor coletivo, tendem à mais aguda hostilidade na estigmatização de grupos outsiders, a ser implacáveis na luta pelo status quo e contra uma queda ou abolição dos limites entre estabelecidos e outsiders. Normalmente são eles quem mais têm a perder no caso de uma ascensão dos outsiders (Elias, 2000: 212).

Há uma declarada estigmatização das trabalhadoras em situações de "alocadas" na fábrica estudada. Os relatos coletados tornam óbvios a hostilidade dos trabalhadores em relação às trabalhadoras e a manutenção da superioridade dos trabalhadores na produção, pelo menos numericamente ${ }^{4}$.

\footnotetext{
${ }^{4}$ Havia, à época da pesquisa, 682 trabalhadores na área produtiva, dos quais 591 eram homens e apenas 91, mulheres.
}

Temáticas, Campinas, 11(21/22):49-74, jan./dez. 2003 
É necessário esclarecer que não há apenas mulheres na condição de RAP, mas homens também. Entretanto, segundo relatos, a situação é mais desagradável para as mulheres, pois há uma maior exigência de desempenho dessas por parte dos seus colegas operários, além de serem preteridas no momento do retorno aos seu grupo.

Para uma trabalhadora da área administrativa entrevistada, o RAP deveria ser acompanhado mais de perto pela empresa, isto porque a maioria das pessoas que estão nestas condições, acabam fazendo coisas que elas não poderiam fazer, ou seja, mais esforço do que deveriam. Esta trabalhadora considera que deveria ter um acompanhamento da área de saúde juntamente com a coordenação, com o intuito de orientar os coordenadores para quais tipos de atividades as pessoas nestas condições podem ser encaminhadas.

A gravidez também é uma fator de afastamento das trabalhadoras dos seus respectivos grupos, pois é preciso antecipar a sua saída, por causa do esforço físico exigido para executar suas funções. Para um dos coordenadores há grupos que querem que sua colega volte a fazer parte do grupo quando terminar sua licença maternidade, porém há outros que querem que ela seja substituída imediatamente à sua saída.

Há um programa desenvolvido pelo setor de Recursos Humanos da empresa Projeto Novidade para as gestantes, que tem por objetivo fazer com que estas se sintam tranqüilas durante a gravidez e permaneçam atualizadas com seu trabalho, para que possam voltar a exercer as mesmas funções sem terem perdido contato com seus projetos, podendo participar dos processos de decisão. Este programa já está sendo realizado na empresa há mais ou menos quatro anos nas áreas de gerência e administração, mas as operárias ainda não estão usufruindo deste benefício. Isto porque, segundo um dos coordenadores, as gestantes têm sua saída antecipada por causa do tipo de trabalho que exercem. A proposta do diretor de RH para este tipo de problema seria criarem uma alocação, na qual teriam uma turma de afastados, seja por gravidez ou RAP. Esta proposta, porém, não surtirá efeito se continuar sendo praticado o mesmo processo de seleção na produção, que 
tem excluído as trabalhadoras. Segundo relatos, o que está ocorrendo é que se uma trabalhadora é afastada, seja por RAP ou gravidez (afastamentos mais prolongados), não consegue retornar ao seu grupo, nem em qualquer outro, já que seus colegas de trabalho preferem, para companheiros de trabalho indivíduos homens e, preferencialmente, que façam parte do seu círculo de amigos.

Foi levantada uma outra questão, que estaria dificultando, em um futuro próximo, o trabalho das mulheres na produção. Estão sendo implementadas, na fábrica, linhas mais rápidas e, nestas máquinas, não há espaço para as mulheres, não tem como elas trabalharem, segundo o relato das entrevistadas. Este fato, na interpretação destas trabalhadoras, está tirando todo o poder de decisão que as mulheres tinham dentro da fábrica, o que retoma a afirmação de Elias (2000), na qual os grupos estabelecidos excluem os outsiders de qualquer chance de poder ou status monopolizando estas chances.

As novas linhas são pesadas, rápidas e exigem muito esforço físico, por isso uma mulher não agüenta trabalhar por muito tempo nestas máquinas, afirma uma das entrevistadas. Segundo um dos gerentes da manufatura, a tendência é que este tipo de máquina, em pouco tempo, seja implantada na fábrica toda. Com isto, não será mais possível haver mulher na linha de produção, na opinião deste gerente. Em minhas observações, pude verificar que estas máquinas exigem muito esforço físico, porém não pode-se afirmar que mulheres não poderão trabalhar nestas linhas de produção. Ainda para gerente da manufatura citado acima, o problema destas máquinas é exatamente o grande esforço físico exigido no final da linhas. Cita o exemplo de países da Europa, onde há fábricas do grupo anglo-holandês de produtos pessoais, nas quais essa operação já foi automatizada, pois, nestes países, há um retorno de capital, o que não ocorre no Brasil, por causa dos baixos salários se comparados ao países europeus. Por exemplo, no caso brasileiro, é mais rentável para a empresa manter um trabalhador do que automatizar o processo. Na opinião deste gerente,

se nós tivéssemos máquinas automáticas no final de linha, com certeza uma mulher poderia trabalhar... até pelo cuidado 
com equipamento, daria muito bem, mas... que não vejo num futuro. Agora daqui a cinco anos, isso tá funcionando, deu pra entender? Infelizmente, é uma pena... então eu vejo a gente migrando pra máquina de alta velocidade, porém, no final de linha ainda manual, tá? E aí, com certeza, você vai ter um esforço físico intenso, daí eu não vejo muito futuro pras mulheres, deu pra entender? Isso é um processo que tá acontecendo... e, cada vez mais, vai afunilando e vai, vai dificultando o trabalho das mulheres, isso eu vejo com a mudança de tecnologia, né?

O gerente geral da fábrica não tem uma visão tão pessimista sobre esse assunto. $\mathrm{Na}$ sua opinião, há uma grande possibilidade de automatizar as operações de final de linha dessas máquinas, como já ocorreram em outros países, considerados por ele "mais adiantados", isto é, nos quais os operários recebem um salário maior do que os das fábricas da subsidiária brasileira do grupo anglo-holandês. Em seu relato, o gerente da fábrica confirma que, atualmente, no Brasil, é mais lucrativo para a empresa manter um trabalhador exercendo esta função do que automatizar a operação. Para ele, este tipo de atitude deixa bem claro que vivemos num sistema capitalista, no qual o lucro é algo extremamente importante:

A empresa tá aqui pra ganhar dinheiro e gerar emprego também, mas, em primeiro lugar, ganhar dinheiro, exatamente isso que é a visão que a gente tem e é nessa visão que a gente trabalha.

O relato deste gerente explicita, apesar do discurso da empresa em estar investindo na melhoria no ambiente de trabalho, que o foco da empresa está nos clientes e fornecedores, pois estes, na visão desta empresa, são aqueles que geram lucro, "esquecendo", apenas quando convém para a empresa, que, para que o produto possa ser vendido este deve ser fabricado e, para isto, há necessidade de trabalhadores e trabalhadoras, por isso a melhoria no ambiente de trabalho não deve ficar restrita ao discurso, mas deve ser aplicada na prática. Quando afirmo que a empresa "esquece" daqueles que realmente trazem lucro para a empresa, que são os trabalhadores e trabalha- 
doras, fazem-no apenas quando isto convém, porque, na maioria das entrevistas, foi relatado que a empresa sempre ressalta aos (as) trabalhadores (as) da área produtiva o quanto são importante para o negócio, que, sem eles, a fábrica não produziria. Além disto este discurso parece ser exclusivamente destinado aos homens, já que, na época da realização da pesquisa, nenhuma solução foi concretamente sugerida para amenizar a situação vivenciada pelas mulheres na área produtiva.

Todos os gerentes da manufatura, assim como os coordenadores desta área, entrevistados e, ainda, o gerente da fábrica e o diretor de Recursos Humanos concordam que há uma falha no processo de recrutamento interno na área de produção. $\mathrm{O}$ diretor de Recursos Humanos considera que chegou o momento de revisarem esta questão, pois isto faz parte do processo. Até o momento em que terminei a pesquisa na fábrica em São Paulo (novembro de 2000), nada havia sido posto em prática para reverter esta situação.

Um dos coordenadores da manufatura ressalta a dificuldade da convivência em grupo e a falta de preparo dos trabalhadores para essa convivência. Os coordenadores acreditam que estes trabalhadores necessitam de ajuda e é o papel deles, juntamente com os gerentes, fornecer essa ajuda e também orientação. O papel dos coordenadores atualmente, segundo relato de um deles, não é mais de vigilância, mas sim, um papel mais social, no qual estão sempre prontos para ouvirem os problemas de seus trabalhadores e, na medida do possível, tentar auxiliá-los na resolução desses problemas. Entretanto, considera que nem sempre isso é possível, já que há um número muito grande de trabalhadores nesta área e, há, também, o trabalho burocrático que, às vezes, toma muito o tempo deles, afirma um dos coordenadores da área produtiva. Segundo um outro coordenador entrevistado, haverá uma mudança que poderá facilitar um maior contato entre eles e seus empregados, que é o aumento no número de coordenadores, passando de cinco para oito. Anteriormente, este contato dos coordenadores com seus empregados era dificultado, pois havia também a troca, a cada dois meses, 
de turma. Justamente quando estavam começando a se familiarizar com os trabalhadores e trabalhadoras de sua turma, tinham que trabalhar com a turma de outro coordenador que tem um modo de trabalho um pouco diferente, afirmam os coordenadores da produção. Com a mudança, irão trabalhar sempre com as mesmas turmas, o que facilitará a aproximação entre eles e seus empregados.

Para o diretor de Recursos Humanos, está faltando investimento, por parte da empresa, em treinamentos não só para os operários, mas também para os coordenadores e gerentes. Sua proposta, para melhorar a escolha dos integrantes dos grupos, seria um programa de formação de operadores para as pessoas que estivessem numa lista de espera e, também, para os interessados em participar do programa, assim teriam um pré-requisito mínimo. Desta forma, haveria uma pré-seleção, na qual estariam os trabalhadores e trabalhadoras que realizaram o programa. Estes participariam, ainda, de uma dinâmica em grupo, que poderia estar sendo auxiliada por um especialista de fora, deixando a decisão final para os próprios grupos. Nesta proposta, haveria também a verificação das dificuldades, que alguns tiveram na dinâmica, para ajudá-los numa próxima oportunidade de vaga.

Um dos coordenadores destaca a importância da escolha final permanecer com os grupos, pois muitos dos trabalhadores da área não vêem apenas o conhecimento teórico do candidato, mas, também, o desempenho dele na sua respectiva linha. Pode-se concordar que a "autonomia" dos grupos, na escolha de seus companheiros de trabalho, deve ser preservada, pois é uma forma de estarem exercendo um certo poder na empresa. Porém a exclusão das mulheres é algo muito sério e grave, que parece não estar sendo dado o devido valor. Isto pode ser constatado na proposta citada acima, idealizada pelo diretor de Recursos Humanos, que não menciona, em nenhum momento, este fato ou como pretende solucioná-lo.

Outro coordenador lembrou que, no início da formação dos grupos, havia um trabalho com os operários fora da fábrica, no qual desenvolviam uma série de atividades, tais como montagem de quebra-cabeças. Também 
chamavam o coordenador da equipe para conversarem sobre as expectativas que um tinha em relação ao outro. Ao longo do processo, isto foi perdido e, na sua interpretação, poderia ser recuperado.

Os comentários citados foram proferidos numa reunião entre coordenadores da produção e a direção do RH em Vinhedo, entretanto, mesmo percebendo que a maioria dos trabalhadores da área produtiva não estão considerando, nas escolhas de seus colegas de trabalho, a competência, a proposta de melhoria concentrou-se neste fator. Houve, deste modo, um desvio do problema, não foi realizada nenhuma proposta, naquela reunião, de solução para a situação em que muitos trabalhadores e, principalmente, trabalhadoras da manufatura estão vivendo na fábrica em Vinhedo. Ainda parece permanecer, nesta fábrica, o que Barbosa (1996/97) denomina de "ideologia da harmonia", na qual o conflito é algo raro e patológico e

que pode ser evitado através das ações gerenciais adequadas, e não como um processo intrínseco à própria vida social. Portanto, todos os esforços são empreendidos para negá-lo de forma explícita. As mais ardorosas discussões são apresentadas como evolução do grupo; o confronto direto de opiniões e de projetos são permanentemente adiados e a intermediação pessoal é a estratégia institucional adotada (Barbosa, 1996-97: 78).

O fato dos coordenadores da área e o diretor de Recursos Humanos sequer terem marcado uma nova discussão para o problema reforça o comentário de Barbosa (1996) sobre a empresa evitar confrontos diretos e adiar projetos, quando estes dizem respeito aos conflitos internos, neste caso entre trabalhadores e trabalhadoras.

\section{UM EXEMPLO COMPARATIVO: A FÁBRICA EM RECIFE-PE}

$\mathrm{Na}$ fábrica localizada na cidade de Recife, Estado de Pernambuco, a seleção interna na área produtiva também é realizada pelos trabalhadores e trabalhadoras, mas, por enquanto, não tem havido as exclusões que estão 
ocorrendo na fábrica em Vinhedo. $\mathrm{Na}$ escolha dos integrantes dos núcleos, todos comentaram que privilegiam a competência do trabalhador, pois, se escolhem alguém que não trabalha bem, o grupo todo é prejudicado.

Em Recife, diferente de Vinhedo, há interferência da coordenação ou do setor de Recursos Humanos, no processo de seleção interno, quando percebem que a escolha está sendo realizada, privilegiando-se o círculo de amizades e não a competência. Como já demonstrado, a escolha dos componentes dos grupos de trabalho na área produtiva, tendo como critério a amizade, vem ocorrendo muito freqüentemente em Vinhedo. Segundo uma dos coordenadores, a intervenção ocorre da seguinte maneira: estes pedem para o grupo colocar os pontos positivos e negativos da pessoa tanto no que se refere ao trabalho quanto ao relacionamento com seus outros colegas, com o intuito de fazê-los perceber que, talvez, estejam observando apenas a questão do bom relacionamento com a pessoa, esquecendo-se que, a partir do momento em que esta pessoa entra num grupo, não se pode trocá-la por outra; é uma decisão permanente, a menos que a mesma seja desligada da empresa. Se algo sair errado com a qualidade do produto ou o produto ficar sem rótulo, a responsabilidade é do grupo todo e não apenas de um de seus componentes. Nesta fábrica, os trabalhadores têm que realizar seu trabalho coletivamente e pensar também enquanto grupo, afirma este coordenador da produção.

Um dos trabalhadores, com quem conversei, considera mais justo o processo de seleção que exija testes escritos e que não permita a escolha dos membros do grupo pelos próprios trabalhadores, pois considera que pode haver escolhas de acordo com as relações pessoais do grupo e não pela competência, como em Vinhedo. Apesar de todos, com quem conversei na fábrica em Recife, afirmarem que não há exclusões no processo de seleção interno, este relato demonstra que já há indício dessa prática, mas que ainda não é percebida de uma maneira mais generalizada como em Vinhedo. É necessário destacar que a fábrica em Vinhedo já tem 22 anos de existência, com 10 anos de grupos semi-autônomos, a fábrica do Recife, apenas 2 anos 
de funcionamento, por isso não é possível prever como este processo estará daqui a 8 anos.

Os trabalhadores e trabalhadoras da área produtiva comentaram que saem junto nos finais de semana, vão a bares, pagodes, a casa de praias e, muitas vezes, os coordenadores desta área os acompanham nos programas, o que estreita o relacionamento entre eles. Talvez seja por este motivo que não têm ocorrido exclusões de mulheres dos núcleos em Recife, já que, na fábrica em Vinhedo, não há este tipo de integração entre trabalhadores e trabalhadoras da área produtiva, porém haveria a necessidade de um investigação mais aprofundada para fundamentar melhor tal questão.

Segundo a coordenadora do RH da fábrica em Recife, há três lemas considerados principais, que procuram sempre reforçar: "Todos os problemas são de todos"; "Não falar de, mas falar com"; "Tem que ter "tesão". Por este motivo, na sua opinião, o ambiente de trabalho é bom, pois procuram sempre estarem atentos ao problemas de seus trabalhadores, mais próximos destes e de seus colegas. Todas as discussões são tomadas em conjunto, procurando deixar as coisas muito claras, afirma esta coordenadora. Cita um exemplo da demissão de um trabalhador da área produtiva, considerado muito competente, mas que não conseguia se relacionar com o seu grupo. A capacitação profissional, segundo seu relato, pode ser dada pela empresa através de treinamentos, mas a mudança de "personalidade" não é possível de ser realiza$\mathrm{da}$, por isso decidiram desligar este trabalhador da empresa, pois reforçam muito o trabalho em equipe como ocorre em Vinhedo, por isso se um integrante do grupo está prejudicando o coletivo por não conseguir trabalhar no "time" (grupo), preferem demiti-lo.

Um dos trabalhadores da área produtiva, com quem conversei, comentou que muitas trabalhadoras na fábrica em Recife possuem iniciativa, se esforçam para realizar o seu trabalho muito bem, e este esforço é reconhecido por seus colegas. No entanto, há também trabalhadoras que acham que, por serem mulheres, não podem realizar determinada tarefa. Este trabalhador comentou, também, que há um núcleo com três trabalhadoras nes- 
ta fábrica que, na sua opinião, conversam muito, o que atrapalharia o trabalho, porém, segundo um dos coordenadores de produção, o núcleo citado é o que menos apresenta problemas no produto pronto, ao contrário do que o trabalhador comentou. $\mathrm{Na}$ opinião deste trabalhador, os homens são mais atentos ao trabalho porque não conversam muito, percebe-se que ele procura ressaltar as qualidades dos trabalhadores e as deficiências das trabalhadoras.

Só ocorreram, até o presente momento, dois casos de gravidez na área da manufatura da fábrica em Recife. Num dos casos, a trabalhadora já vinha apresentando um problema de relacionamento com o grupo, por isto não retornou a seu núcleo e está em situação de "ajudante de produção", sendo que nem a própria trabalhadora demostrou interesse em retornar a ele, segundo comentários. No segundo caso, a trabalhadora ainda está grávida, mas o núcleo já se manifestou assegurando-a de que ela retornará ao mesmo quando cumprir a licença maternidade. Como minha observação na fábrica em Recife foi apenas exploratória, não tenho como afirmar se o discurso dos (as) trabalhadores (as) está ocorrendo na prática cotidiana de trabalho. As falas destacam um forte diferença com a fábrica em Vinhedo, entretanto isto pode ter acontecido exatamente com este propósito, diferenciar-se e mostrar-se melhor. Tais afirmações, porém, são apenas conjecturas que merecem um maior aprofundamento.

Tanto em Vinhedo quanto em Recife, na área de processo dos produtos, na operação das empilhadeiras, nas oficinas mecânicas e elétricas só há homens, cuja justificativa deve-se ao tipo de esforço físico necessário, chegam a pegar pesos de 15 a $30 \mathrm{~kg}$. Na ocasião da entrevista com os trabalhadores da área produtiva em Vinhedo, comentei com estes que muitas horis$\operatorname{tas}^{5}$ gostariam de trabalhar como empilhadeirista (dirigindo empilhadeiras). A reação destes trabalhadores a este comentário foi muitos risos e ainda responderam que as mulheres já são ruins no trânsito, dirigindo um carro,

\footnotetext{
${ }^{5}$ Nas fábricas estudadas os(as) operários (as) recebem por hora, por isto a denominação horistas. $\mathrm{Na}$ área administrativa como o salário é pago por mês são considerados mensalistas.
}

Temáticas, Campinas, 11(21/22):49-74, jan./dez. 2003 
imaginem dirigindo uma empilhadeira. Uma das entrevistadas comentou que, se elas se candidatam a uma vaga considerada "masculina", tais como mecânica e empilhadeirista, são motivo de risos o ano todo. Entretanto, um outro entrevistado ressaltou que existem mulheres que são muito boas motoristas. Outro horista lembrou que havia um colega que trabalhava como empilhadeirista e era muito ruim como tal, disse que quando eles o avistavam, saíam do caminho com medo de serem atropelados.

Pode-se observar algo parecido na pesquisa de Gonzáles(1999) na área de seguros, esta observa que as vendedoras de seguros são contratadas, em sua maioria, para a área de seguro de vida, devido às características emocionais e físicas, consideradas melhores para vender seguros nesta área; com isto, semelhantes vendedoras acabam sendo excluídas das outras áreas.

La construcción dicotómica de los valores de género, que plantea lo masculino y lo feminino como realidades complementarias, opuestas y excluyentes, em la medida que adscribe a las mujeres a determinados ramos em base a su componente emocional, las excluye de aquellos em que se enfatiza el componente racional: cálculo financiero o riesgos industriales, por ejemplo. Así, si es más funcional como vendedora de productos de Vida, no lo es como vendedora de productos de Muerte, em el ramo de Decesos (Gonzáles, 1999: 293).

Este fato indica que não está havendo diferenciais na avaliação do desempenho das mulheres conforme setores de Indústria e de Serviços. Na fábrica da Divisão de Produtos Pessoais em Vinhedo-SP, segundo os vários relatos, há também uma construção dicotômica dos valores de gênero como acontece na pesquisa de Gonzáles. A área produtiva, por exemplo, é representada como masculina, por isso a exclusão evidenciada das trabalhadoras desta área.

A maioria dos trabalhadores entrevistados, da área de produção, comentaram que, quando trabalham com uma mulher, não podem conversar sobre quase nada, têm que ficar comportados, e eles não gostam de ter que assumir este tipo de comportamento. Na pesquisa realizada por Anna 
Pollert (1996), as entrevistas também revelaram que, quando os homens estão acostumados a trabalharem como único sexo, estes inventam desculpas para excluírem as mulheres deste meio, tais como,

'not being able to use bad language in front of women' to women allegedly 'getting away with more' with team leaders and not being willing to do the 'filthy' cleaning jobs underneath the machinery (Pollert, 1996: 188).

Um outro dado interessante foi relatado, por um dos horistas entrevistado, sobre uma experiência que teve com uma colega horista na ocasião da escolha de um componente para o núcleo. A trabalhadora em questão queria escolher um trabalhador que ela não conhecia, mas tinha referência sobre sua competência, e os outros integrantes do núcleo queriam uma outra pessoa, que eles já conheciam. O entrevistado disse ter batido de frente com esta trabalhadora e, por este motivo, tiveram uma pequena discussão. $\mathrm{Na}$ interpretação do entrevistado, esta horista provocou a discussão para entrar em oposição. No final do relato, diz com orgulho: Mas ela perdeu pra mim. Para este horista, tem mulheres que não se valorizam, entretanto, durante todo o seu relato, este entrevistado não levantou, nem por um momento, a questão do candidato à vaga ser competente ou não, o que conduz à interpretação de que este queria mostrar a sua superioridade à trabalhadora, estando implícitas as relações de poder. O poder é tratado neste artigo também como uma relação, como proposto por Michel Foucault (1984), por isto este não está situado num lugar privilegiado ou exclusivo, mas disseminado por toda a sociedade, sendo exercido como uma multiplicidade de relações de forças. Na fábrica estudada, essas relações não estão presentes apenas nos altos níveis hierárquicos da empresa, mas também em todas as suas extensões, ou seja, da produção à gerência.

Para uma das trabalhadoras da produção entrevistada, o trabalho na produção é muito mais estressante para a mulher do que para o homem, porque estes exigem muito mais das trabalhadoras. 
A gente tem que se "dar" muito mais do que o homem. Essa diferença é gritante e acaba com a mulher. É muito difícil você encarar os homens de frente, tem que ser muito mulher pra encarar.

Este relato mostra que as trabalhadoras da referida fábrica são cobradas o tempo todo por serem mulheres, o que, na representação dos trabalhadores, significa que não possuem a mesma competência e devem sempre estar provando a sua capacidade, mas, mesmo que consigam, não é o suficiente para serem tratadas como "iguais", isto é, como trabalhadoras.

A maioria das entrevistadas disseram que o horário de trabalho, na área produtiva, é muito mais complicado conciliar trabalho e vida pessoal para as mulheres que têm filhos e são divorciadas, pois, no turno da noite, além de terem que deixar as crianças aos cuidados de uma empregada durante a noite toda, elas terão que ficar com esta pessoa também na parte da manhã para que as mães possam dormir, por isso preferem não ter filhos.

Uma outra entrevistada fez uma ressalva de que não há condições de haver um núcleo só de mulheres, ou com uma maioria de mulheres, por causa do esforço físico, já que há certos tipos de trabalho que necessitam da ajuda de um homem. Outro problema apontado para a organização de um grupo de trabalho composto apenas por mulheres referem-se às fofocas, acham que, quando há apenas mulheres trabalhando juntas, surgem muitas fofocas, mas vêem a necessidade de pelo menos uma mulher em cada núcleo. Segundo uma delas, há alguns homens na fábrica que compreendem o fato das mulheres terem certos limites de força, mas há outros que dizem: você ganha igual, então tem que trabalhar igual, assim elas têm que realizar o trabalho, mesmo sabendo que exigirá um esforço quase impossível de executar, podendo mesmo acontecer algum acidente, afirma uma das operárias entrevistadas. Os trabalhadores utilizam a equiparação salarial para negar auxílio às trabalhadoras em Vinhedo; como já citamos, em Recife prevalece a concepção de que a mulher não deve fazer muito esforço físico, pois é "frágil". 
Um dos mensalistas entrevistado da fábrica em Vinhedo comentou que o biotipo da mulher é diferente do homem, por isso uma mulher não irá trabalhar na produção num lugar que tenha que pegar peso. Outro mensalista comenta que, na produção, não há mais distinção de sexo para o trabalho, ganham o mesmo salário, por isso devem desempenhar as mesmas funções. Cita um exemplo de uma trabalhadora da produção:

O que o L. falou da questão da produção em si... mas hoje os homens da produção não estão destinguindo se é mulher ou não, tá? Se tão ali, recebendo o mesmo salário, tem que fazer as mesmas coisas, inclusive a questão do peso, tá? Eu tive alguns feedbacks ali de alguns funcionários ali que... tinha uma senhora que saiu recentemente... ela não agüentava carregar, ela tinha problema de pressão, pegar um peso muito forte. Eles falaram: Olha, minha amiga, você está recebendo o mesmo salário que eu, você tem que fazer a mesma coisa... Até ela ficou chateada com essa questão, mas eu achei até válido porque foi bom pra ela, tá? Porque ela viu que não tava conseguindo mais, e ela pediu desligamento, eu acho que estão ganhando o mesmo salário e exercendo a mesma função, estão fazendo as mesmas coisas, não depende do quê.

Um outro mensalista, diante deste comentário, relata que seria, neste caso, necessário ter bom senso, o colega horista poderia estar ajudando-a nos trabalhos que exigissem um maior esforço físico - como ocorre em Recife.

Não se pode negar que há diferenças biológicas entre homens e mulheres, entretanto, estas não podem ser utilizadas para excluir as mulheres de alguns trabalhos que exijam um pouco mais de esforço físico. Por outro lado, estas diferenças biológicas também acarretam certas limitações às mulheres, cujo corpo, se não exercitado, não possui força suficiente para trabalhos que exijam muita força física.

Muitas pesquisas sobre gênero e trabalho (Rizek e Leite, 1998; Cockburn, 1994; Lobo, 1991) observam que as trabalhadoras recebem um salário menor do que os trabalhadores. Na fábrica em Vinhedo, como já observado, há equiparação salarial, entretanto, como pode-se observar nos 
relatos citados acima, este fato também tem se tornado um problema para as trabalhadoras, que, mesmo não tendo condições físicas para realizar determinadas tarefas, são obrigadas a exercê-las, pois teoricamente estão numa posição de "igualdade" proporcionada pelos salários equivalentes. Na prática, esta igualdade está restrita apenas aos salários e, nas condições de trabalho, há uma grande divergência entre eles, como tem sido relatado pelos próprios trabalhadores desta fábrica.

Um dos horistas entrevistado comentou que faz pouco tempo que está casado, e isso mudou muito a sua vida, pois tem ajudado sua mulher a lavar roupa, utilizando a máquina de lavar, o que considerou ser uma tarefa fácil. Disto tirou a conclusão de que o serviço da mulher em casa é muito fácil. Nem todos concordaram com ele. Um deles disse que devemos valorizar as mulheres, porque as que trabalham fora geralmente também fazem os serviços domésticos (a dupla jornada). Outro acrescentou que mesmo a mulher que não trabalha fora dá um duro danado em casa e, muitas vezes, o marido chega e diz que ela não fez nada o dia todo (fez alusão a uma matéria exibida pelo Fantástico, programa da Rede Globo de Televisão, no qual havia abordado este assunto).

Outros lembraram o quanto o serviço deles na fábrica é muito cansativo, e há mulheres que, ao saírem de lá, terão que chegar em casa e enfrentar outros serviços também pesados. Um deles disse: Olha... é difícil. Comentou que, ao chegar em casa, não tem vontade de fazer nada, pois está muito cansado. Um entrevistado (horista) comentou que, atualmente, as mulheres estão ocupando espaços que há dez anos não ocupavam, mas reconhece que há ainda muito preconceito. Outro disse algo muito interessante:

A mulher não está ocupando espaço (provavelmente ele quis dizer que a mulher não está tirando o espaço do homem), ela está ocupando um espaço que é dela por direito, porque, na verdade, os direitos são iguais, não é verdade? Então ela ficou muito tempo enclausurada dentro de casa, agora ela está ocupando o espaço dela. E era coisa de... uns quinhentos anos atrás, ela já ter ocupado, né? 
Este trabalhador tem uma visão muito positiva sobre as mulheres no mundo do trabalho, reforçando a idéia de que não é possível fazer generalizações sobre o preconceito e discriminação dos homens em relação às mulheres.

Apesar das conquistas das mulheres no trabalho, segundo FIBGEPNAD em 1999 as mulheres representavam 40, 2\% dos 71,6 milhões de trabalhadores no Brasil, Segnini (1998), ao pesquisar as trabalhadoras do setor bancário, observa algo interessante que pode-se aplicar também a este caso, ou seja, na família, estas continuam a

vivenciar papéis tradicionalmente atribuídos à mulher, no contexto de uma sociedade que, apesar de capitalista, ainda expressa valores culturais observados em uma sociedade patriarcal (Segnini, 1998: 175).

Os relatos citados confirmam que as trabalhadoras da fábrica estudada desempenham funções que os próprios operários consideram cansativos e, ainda, ao chegarem em suas casas, deverão desempenhar as funções de dona-de-casa. Muitas trabalhadoras divorciadas comentaram que um dos fatores que as levaram ao divórcio foi a incompreensão de seus maridos quanto ao cansaço destas após um dia ou uma noite de jornada. Elas relataram que seus maridos queriam chegar em casa e vê-las bonitas e cheirosas, prontas para cumprirem seus papéis de esposas. Neste caso específico, estavam se referindo às relações sexuais, porém, muitas vezes, não estavam dispostas e eram muito cobradas por seus companheiros. A pressão sofrida, tanto no trabalho quanto em casa, acabaram por levá-las a uma escolha entre o profissional e o pessoal, no qual muitas acabaram optando pelo profissional.

Como afirma Segnini (1998),

efetivamente, a casa, os filhos, alimentação, educação, saúde e tantos outros aspectos da vida familiar são considerados trabalhos 'femininos', mesmo para aquelas mulheres que ocupam altos postos na hierarquia do banco (Segnini, 1998: 176). 
Os coordenadores da produção da fábrica em Vinhedo acreditam que a situação das mulheres possa melhorar na produção com a contratação de uma coordenadora. As próprias trabalhadoras da produção gostariam que houvesse uma coordenadora na área, já que há certas particularidades nas mulheres, como cólicas menstruais, nas quais se sentem constrangidas em conversar com seus coordenadores sobre o assunto, porém não têm escolha. A menstruação causa outro problema, já que não podem ir muito ao banheiro, só quando tiver uma outra pessoa para ficar em seu lugar. Utilizam este espaço não quando têm vontade, mas sim quando têm oportunidade, por isso já aconteceu de uma delas ter manchado a calça e ter que pedir uma outra emprestada, passando por um terrível constrangimento, segundo seu relato. Comentaram também que, quando surgem vagas para o cargo, muitas se inscrevem, mas nunca são chamadas a exercê-lo. Comentaram também, que nunca houve, na fábrica em Vinhedo, uma coordenadora.

A proposta do diretor de RH inclui a contratação de uma coordenadora, que, segundo informação obtida na fábrica em Recife, já foi contratada uma, que está em treinamento para exercer o cargo. Na fábrica localizada em Recife, desde o início das suas atividades, há uma coordenadora na área produtiva. Esta comentou que, no início de seu trabalho na fábrica em Recife, sentiu-se discriminada; muitas informações eram dadas a seus colegas e a ela não. Mas, atualmente, considera que esta sensação se devia ao fato de uma experiência anterior, que também ocorreu na área produtiva em Recife, local considerado predominantemente masculino e sofreu, por isto, muita discriminação. Na sua concepção, quando foi trabalhar na Divisão de Produtos Pessoais, ainda estava um pouco na defensiva por causa da experiência anterior. No momento não sente mais nenhuma discriminação, ao contrário, é muito respeitada por seus colegas homens. São 4 coordenadores de produção, sendo apenas uma mulher. Para esta, é muito importante ter uma mulher na coordenação, pois as trabalhadoras sentem-se mais à vontade para expor os seus problemas e intimidades. Considera também importante a presença das mu- 
lheres nos núcleos, pois para ela as mulheres dão certo equilíbrio aos núcleos; a maioria se esforça em realizar as mesmas tarefas de seus colegas trabalhadores e procuram sempre tomar a iniciativa na execução das mesmas.

Como estive em Recife por um período muito curto, não pude verificar mais detidamente as diferenças entre o discurso e a prática cotidiana dos trabalhadores e trabalhadoras, por isso tomei esta fábrica apenas como exemplo comparativo, para mostrar que, apesar destas duas fábricas produzirem os mesmos tipos de produtos, devendo seguir as mesmas normas de trabalho, possuem diferenças na aplicação destas normas e no tratamento dados a seus (suas) trabalhadores (as).

\section{CONSIDERAÇÕES FINAIS}

As trabalhadoras entrevistadas, em sua maioria, concordam que o processo de escolha praticado anteriormente a 1990, no qual eram os coordenadores que escolhiam os componentes dos grupos, era mais favorável a elas, pois sempre haviam mulheres neles. Hoje, há grupos que não possuem mulheres entre seus integrantes. É preciso lembrar que as operárias estão vivendo uma situação de exclusão, por isso não estão conseguindo perceber a relativa "autonomia" que foi proporcionada pelo direito dos trabalhadores à escolha final dos integrantes dos grupos. Não estão vendo que esta é uma forma de poder de decisão na empresa. Como destacado anteriormente, o poder é considerado neste artigo como uma relação, de acordo com Michel Foucault (1984), por isto este não está situado num lugar privilegiado ou exclusivo. $\mathrm{Na}$ fábrica estudada, essas relações estão dispersas em todas as suas extensões, ou seja, da produção à gerência.

A não percepção do poder de decisão proporcionada pelo processo de seleção interno na área produtiva pode estar ocorrendo porque os operários não estão sabendo trabalhar muito bem com essa "autonomia", já que parece estar prevalecendo a necessidade de distinção entre os trabalhadores já que homens e mulheres exercem as mesmas funções e recebem um mes- 
mo salário, numa área que somente nesta fábrica e em sua outra fábrica da mesma divisão localizada em Recife-PE há trabalhadoras. Como não é possível haver distinção entre trabalhadores e trabalhadoras na questão da qualificação, salário e funções, como acontece em outras empresa, nesta fábrica o sexo parece ser o diferencial entre eles. Por isso para adquirir uma certa superioridade, consequentemente poder em relação às trabalhadoras, os trabalhadores procuram inferiorizá-las excluindo-as dos núcleos. Deste modo, a escolha dos integrantes dos núcleos de trabalho é vista apenas como um instrumento utilizados pelos trabalhadores para estigmatizar as operárias e assim manterem sua predominância "masculina" na área produtiva da fábrica.

Fazendo várias ressalvas, o processo seletivo interno é, de certa forma, positivo, necessita, porém, como os próprios coordenadores apontaram, ser melhor trabalhada ou mesmo reformulada, para garantir o direito a todos (as) trabalhadores (as) de poderem exercer seu poder de decisão na escolha de seus companheiros (as) de trabalho, sem discriminações.

ABSTRACT: The present paper examines the exclusion mechanisms observed in a study on the change processes that occurred in two different companies: the first, a manufacturing plant located in the interior of the state of São Paulo with a branch in Recife and linked to an Anglo-Dutch group. In this article, the emphasis falls on the ways of exclusion of female labor observed in the production sector of the manufacturing plant during the selection process, on the occasion of pregnancy or sick leaves, and at resuming work, when female workers are classified as allocated.

KEYwORDS: Productive restructuring; Exclusion mechanisms; Symbolic dimension; Change processes.

\section{REFERÊNCIAS BIBLIOGRÁFICAS}

ABREU, Alice Rangel de Paiva. Mudança tecnológica e gênero no Brasil. Novos Estudos CEPRAP, n. ${ }^{\circ}$ 35, março de 1993.

BARBOSA, Livia. Análise Cultural: Elida Gibbs. Relatório de análise cultural realizado na fábrica e centro empresarial Elida Gibbs, 1996/97. 
COMBES, Danièle e HAICAULT, Monique. Produção e Reprodução. Relações sociais de sexo e de classes In KARTCHEVSKY-BULPORT, Andrèe. O sexo do trabalho. Rio de Janeiro: Paz e Terra, 1986.

DOUGLAS, Mary. Poderes e Perigos In Pureza e Perigo, São Paulo: Perspectiva, 1976.

ELIAS, Norbert e SCOTSON, John L. Os Estabelecidos e os Outsiders, Rio de Janeiro: Jorge Zahar Editor, 2000.

FLEURY, Afonso Carlos Côrrea. Organização do trabalho na indústria: recolocando a questão nos anos 80 In FLEURY, Maria Tereza Fleury e FISCHER, Rosa Maria. Processo e Relações de Trabalho no Brasil, São Paulo: Atlas, 1985.

GONZÁLES, Carmen Mozo. Género y Nuevas Profisiones: El Sector Seguros en Sevilla, Sevilla: Área de Cultura, Ayuntamiento de Sevilla, 1999.

HIRATA, Helena e Kergoat, Danièle. A classe operária tem dois sexos. Revista Estudos Feministas, vol. 2, n. ${ }^{\circ}$ 3, 1994.

POLLERT, Anna. Team Work' on the Assembly Line In ACKERS, P. et alli The New Workplace and Trade Unionism, Routledge, Londres, 1996.

RIZEK, Cibele Saliba e LEITE, Márcia de Paula. Dimensões e Representações do Trabalho Fabril Feminino, Cadernos Pagu, 10, 1998.

SEGNINI, Liliana. Mulheres no Trabalho Bancário: Difusão Tecnológica, Qualificação e Relações de Gênero. São Paulo: Editora da Universidade de São Paulo, 1999, cap. 1 e 2.

TURNER, Victor W. Liminaridade e "Comunitas" In O Processo Ritual: estrutura e anti-estrutura, Petropólis: Vozes, 1974. 